\title{
AN EXPERIMENTAL STUDY ON SUSTAINABILITY OF HISTORICAL WOODEN BUILDINGS EXPOSED TO OPEN SEA STREAMS
}

\author{
Esra Celik, Ismail Cengiz Yilmaz, Deniz Yilmaz \\ Istanbul Arel University \\ TURKEY \\ (Received July 20I9)
}

\begin{abstract}
This research deals with the impact of the microclimate on historical wooden buildings exposed to open sea streams. The Florya Ataturk Marine Mansion in Istanbul, erected on the sea, totally defenceless to weather and sea effects, has been selected as representative case study for many other buildings located in Bosphorus line. In order to address the effect of the environment on the building exposed to open sea streams microclimatic data were collected for one year. The synergistic effect of the sea-salt aerosol and microclimatic conditions were discussed for the assessment of the impact of the marine environment on the durability of the Mansion, identifying the more vulnerable parts of the building as well as the more critical periods. The results indicate that while moisture content changes from $20.9 \%$ to $36.7 \%$ and temperature changes from $14.1^{\circ} \mathrm{C}$ to $28.7^{\circ} \mathrm{C}$, thermal conductivity coefficient changes from $0.18 \mathrm{~W} \cdot \mathrm{m}^{-1} \mathrm{~K}^{-1}$ to $0.26 \mathrm{~W} \cdot \mathrm{m}^{-1} \mathrm{~K}^{-1}$, according to the facade of the building and the season as similar to previous studies.
\end{abstract}

KEYWORDS: Wood structures, historical buildings, thermal conductivity, sustainability.

\section{INTRODUCTION}

Finely worked wood was the predominant construction material for the majority of traditional Turkish houses, including yalıs, a house constructed at immediate waterside and usually built with an architectural concept that takes into account the characteristics of the coastal location. The hundreds of waterside residences, mostly dating from the $19^{\text {th }}$ century, sprinkled along the Bosphorus in Istanbul, constitute one of the city's landmarks.

It is well known that the marine microclimate is extremely dangerous for the conservation of movable and immovable heritage assets, especially which are constructed by wood material, because it intensifies natural weathering through the deposition of sea-salt particles that is controlled by various environmental parameters. Marine aerosol intensifies the natural 
weathering through the deposition of sea-salt particles that may react with the surfaces and structures depending on the environmental parameters. Relative humidity variations can cause crystallization-dissolution cycles of salts which could penetrate into the material and generate decay. Buildings in marine environment are also vulnerable to biodegradation that is very effective in humid environments. As a consequence, structures and objects exposed to sea water and high moisture levels required frequent maintenance and restoration works.
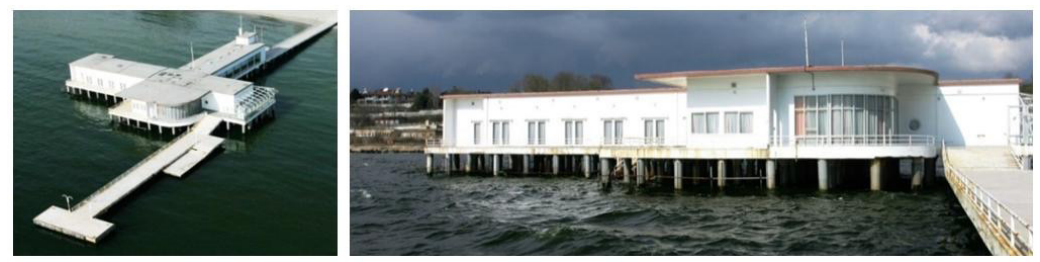

Fig. 1: Florya Ataturk Marine Mansion (experimental object).

The importance of microclimatology in the preservation and restoration of cultural heritage is widely recognized (Bernardi 2008, Camuffo 2014, Thomson 1986). The study of microclimate is fundamental in the assessment of the weathering surfaces exposed to outdoor and indoor environments (Becherini et al. 2010, Becherini et al. 2013, Camuffo et al. 2004, Fojtik 2018) as the microclimatic conditions play a key role in the starting and developing not only of physical processes, but also chemical and biological ones, often acting in synergism. Moreover, in literature are reported several examples of unsuitable thermal-hygrometric conditions in historical buildings that are usually built with traditional materials, generally stone and wood, that have a bad thermal and hygrometric behaviour (Thomson 1986, Donovan 1986, Mills et al. 1987, Michalski 1990, Grinzato et al. 2002, Abuku et al. 2009, Moradias et al. 2012). In addition, the marine environment can be considered particularly critical for conservation issues, as the atmosphere is enriched with particles that are naturally generated by the action of wind on the seawater surface. Several authors have showed that marine environments that are charged with salts cause deterioration of the construction materials (Davide 2014, Meira et al. 2006, Morcillo et al. 2000, Erkal et al. 2012). Anyhow, most of the literary studies are focused on concrete structures and stone materials (Alao et al. 2014, Chabas et al. 2000), or they address only the chemical weathering due to sea-salts aerosol (Chabas et al. 2000, Zezza et al. 1995, Stefanis et al. 2005). Nevertheless, a deep and comprehensive research about microclimate and sea effects on historical structures is rather lacking in literature. The present study wants to provide an integrated approach to the problem of the impact of microclimate and sea streams on historical buildings, following the example of other studies in literature applied to other topics (Nava et al. 2010).

In this paper it is aimed at studying the impact of the microclimate on historical buildings exposed to open sea streams, through the representative case study of the Florya Ataturk Marine Mansion (Fig. 1), a historic presidential residence located offshore in the Sea of Marmara in the Florya neighbourhood of the Bakirkoy district in Istanbul. Built in 1935 by the municipality of Istanbul for Atatürk's recreational use, it is erected on steel piles driven into the seabed and linked to the mainland by a wooden pier of about $70 \mathrm{~m}$ in length. The building is totally defenceless to weather and sea effects, therefore periodically and costly restoration work is made. The damage patterns observed are similar to other historical buildings located nearby the Bosphorus strip mainly because of sea effect and salt deterioration.

The research is aimed at studying the impact of the marine microclimate on the Florya Ataturk Marine Mansion in Istanbul, selected as reference for the huge number of wooden buildings alongside the Bosphorus exposed to open sea streams. 
The impact of the marine environment on the durability of the mansion was assessed by the analysis of the meteorological and microclimatic data in synergy with the severe sea effects. The more vulnerable parts of the building as well as the more critical periods were identified. The ambient conditions that the material is exposed to each season are different, which leads to different deformations on the material. These deformations can also affect the heat permeability of the material positively or negatively. The microclimate and sea effects were investigated for the environmental risk assessment of the Florya Ataturk Marine Mansion. The microclimate nearby the mansion was monitored continuously for one year taking also into account the local climatology. Moisture content and surface temperature of the walls were measured outside. Moisture and temperature figures were analysed on daily, weekly, monthly and yearly basis. Also, thermal conductivity coefficients were measured at certain periods during the year by placing wood materials of the same properties on the building facades where on-site measurements were made.

\section{MATERIAL AND METHODS}

In this study, the temperature and humidity values of the surface of the building were measured with hand-held measuring instruments that do not damage the building since it is a historical building. Moisture measurement (moisture meter Testo-616) and for the surface temperature measurement Testo 905-T2 was used. For heat conduction coefficient measurements; the samples are subjected to the equinox periods determined as critical periods, in June-JulyAugust, September-October-November, December-January-February, March-April-May, the front and left side facades selected as vulnerable partitions (the front with the most sunbathing time and the left side with the least sunshine duration). Then the samples were subjected to a thermal conductivity test in the laboratory with a thermal conductivity meter (thermal conductivity meter Cole-Parmer) by comparison method according to the test standard (Fig. 2). In this measurement device using the comparison method, the heat conduction coefficient of the sample is determined using a reference body whose heat conduction coefficient is known. The temperature difference was established by placing the sample and reference body between the heat source and the heat sink. The amount of heat energy passing through the sample and reference body is the same. The heat transfer coefficient of the sample was determined by using the upper and lower thermal values of the sample and the heat conduction coefficient of the reference body.

The wooden material used in the building is scots pine. When the literature is examined, holocellulose, alpha cellulose and lignin content were found to be approximately 71-74\%, 47-49\% and 26-29\% respectively (Tutus et al. 2010, Kilic et al. 2010, Abuamoud et al. 2018, Zborowska et al. 2007) (Tab. 1). Standard sized samples of this pine material are produced and placed on the front and side of the building. Specimens produced according to the test device have a circular cross-section of $11.28 \mathrm{~cm}$ in diameter (Fig. 2).

Tab. 1: Main chemical components of scots pine (Tutus et al. 2010, Kiluc et al. 2010, Abuamoud et al. 2018, Zborowska et al. 2007).

\begin{tabular}{|c|c|c|c|}
\hline Chemical components & Holocellulose & Alpha cellulose & Lignin \\
\hline Ratio & $71-74 \%$ & $47-49 \%$ & $26-29 \%$ \\
\hline
\end{tabular}




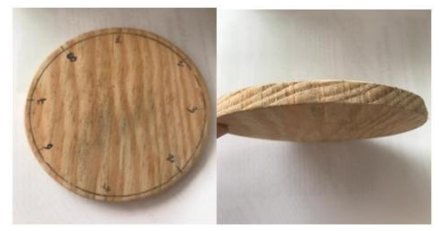

Fig. 2: A cross-section of pinewood specimen.

Fourier law was used to calculate the heat transfer coefficient by using the temperature values obtained from the comparison method. Assuming that there is no heat transfer in the radial direction from the sample and reference body, the amount of heat passing through the sample is equal to the amount of heat passing through the reference material.

\section{RESULTS AND DISCUSSION}

All the data collected during the first year with automatic and manual devices was analysed in their spatial and temporal trends in order to have a complete picture of the microclimate inside the mansion and outside on the basis of weekly, monthly and yearly periods. The monitoring of the microclimate on the Florya Ataturk Marine Mansion was performed for one year with automatic devices. The moisture content of the outer and inner walls of the building was measured manually in the different seasons. In addition, in summer and winter the thermal behaviour of inner wall surfaces differently oriented was investigated by means of thermography. The measured moisture, temperature and calculated thermal conductivity coefficient values are presented in Tabs. 2, 3 and 4, resp.

Tab. 2: Monthly moisture content (MC) values measured in site.

\begin{tabular}{|c|l|l|c|}
\hline Year & \multicolumn{1}{|c|}{ Months } & \multicolumn{1}{c|}{ Facade } & MC (\%) \\
\hline $\mathbf{2 0 1 8}$ & June-July-August & Front & 36.7 \\
\hline $\mathbf{2 0 1 8}$ & June-July-August & Left side & 32.9 \\
\hline $\mathbf{2 0 1 8}$ & September-October-November & Front & 27.8 \\
\hline $\mathbf{2 0 1 8}$ & September-October-November & Left side & 24.7 \\
\hline $\mathbf{2 0 1 8}$ & December-January-February & Front & 22.8 \\
\hline $\mathbf{2 0 1 8}$ & December-January-February & Left side & 20.9 \\
\hline $\mathbf{2 0 1 8}$ & March-April-May & Front & 33.1 \\
\hline $\mathbf{2 0 1 8}$ & March-April-May & Left side & 27.4 \\
\hline
\end{tabular}

Tab. 3: Monthly temperature degrees measured in site.

\begin{tabular}{|c|l|l|c|}
\hline Year & \multicolumn{1}{|c|}{ Months } & \multicolumn{1}{c|}{ Facade } & Temperature $\left({ }^{\circ} \mathbf{C}\right)$ \\
\hline $\mathbf{2 0 1 8}$ & June-July-August & Front & 28.7 \\
\hline $\mathbf{2 0 1 8}$ & June-July-August & Left side & 24.1 \\
\hline $\mathbf{2 0 1 8}$ & September-October-November & Front & 21.9 \\
\hline $\mathbf{2 0 1 8}$ & September-October-November & Left side & 20.3 \\
\hline $\mathbf{2 0 1 8}$ & December-January-February & Front & 18.7 \\
\hline $\mathbf{2 0 1 8}$ & December-January-February & Left side & 14.1 \\
\hline $\mathbf{2 0 1 8}$ & March-April-May & Front & 22.8 \\
\hline $\mathbf{2 0 1 8}$ & March-April-May & Left side & 19.3 \\
\hline
\end{tabular}


Tab. 4: Monthly calculated thermal conductivity coefficients.

\begin{tabular}{|c|l|l|c|}
\hline Year & \multicolumn{1}{|c|}{ Months } & \multicolumn{1}{c|}{ Facade } & $\mathbf{k}\left(\mathbf{W} \cdot \mathbf{m}^{-\mathbf{1}} \mathbf{K}^{-\mathbf{1}} \mathbf{)}\right.$ \\
\hline $\mathbf{2 0 1 8}$ & June-July-August & Front & 0.26 \\
\hline $\mathbf{2 0 1 8}$ & June-July-August & Left side & 0.24 \\
\hline $\mathbf{2 0 1 8}$ & September-October-November & Front & 0.21 \\
\hline $\mathbf{2 0 1 8}$ & September-October-November & Left side & 0.20 \\
\hline $\mathbf{2 0 1 8}$ & December-January-February & Front & 0.19 \\
\hline $\mathbf{2 0 1 8}$ & December-January-February & Left side & 0.18 \\
\hline $\mathbf{2 0 1 8}$ & March-April-May & Front & 0.24 \\
\hline $\mathbf{2 0 1 8}$ & March-April-May & Left side & 0.21 \\
\hline
\end{tabular}

According to this; the difference in temperature and moisture between the front and left side facades is clearly visible. Accordingly, the heat transfer coefficient is significantly higher in the samples placed on the facade, which is heavily exposed to microclimate effects, than the samples placed on the other facade. According to this; it is important for building sustainability to concentrate the protection methods and frequency on the front facade compared to the side facade.

Graphs summarizing the variation of the thermal conductivity coefficient depending on temperature and air humidity are presented in Fig. 3 and Fig. 4.

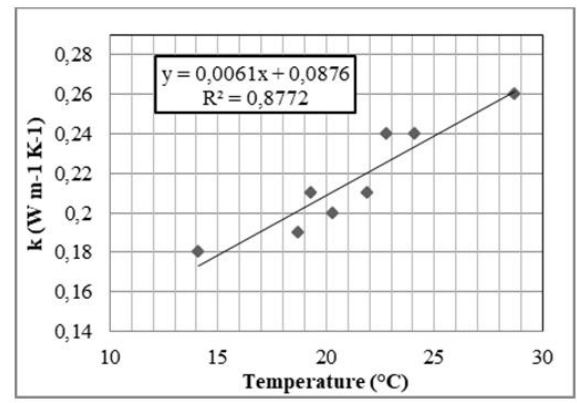

Fig. 3: Thermal conductivity coefficient according to temperature.

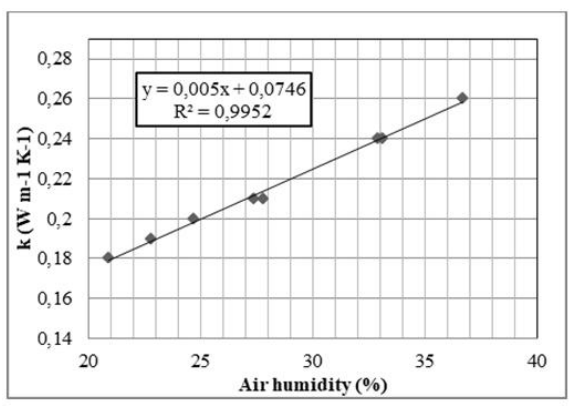

Fig. 4: Thermal conductivity coefficient according to air bumidity.

When we compare these values with the studies in the literature, it can be seen that similar results are obtained. In their study which analyses the variations of thermal conductivity under various temperatures, Dell'Isola et al. (2012) experimentally showed that the thermal conductivity coefficient of pinewood increased with increasing temperature and water content ratios (Fig. 5 and Fig. 6). 


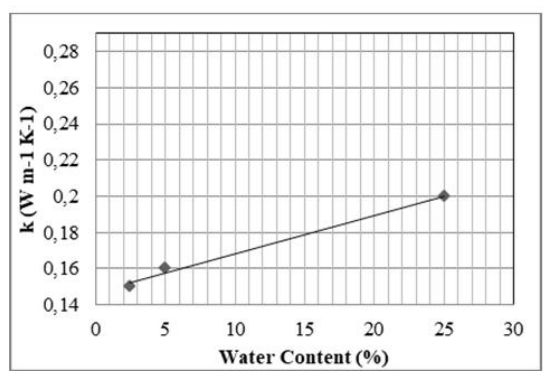

Fig. 5: Thermal conductivity coefficient according to water content at $10^{\circ} \mathrm{C}$. (Dell'Isola et al. (2012)).

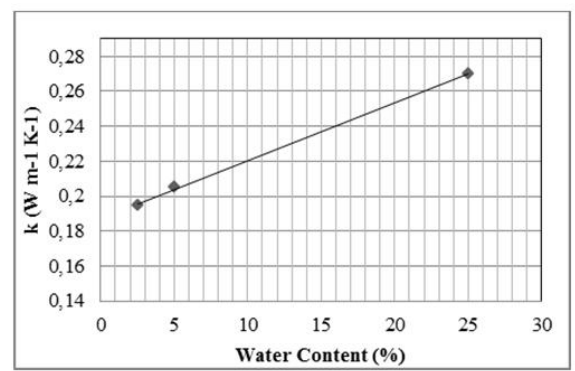

Fig. 6: Thermal conductivity coefficient according to water content at $30^{\circ} \mathrm{C}$. (Dell'Isola et al. (2012)).

Troppova et al. (2015) examined in their study the variability of the thermal conductivity coefficient of wood-based fibreboards according to the increase in temperature depending on air humidity from $-10^{\circ} \mathrm{C}$ to $60^{\circ} \mathrm{C}$. It was found that the moisture content of material increases from $0 \%$ to $14.29 \%$ and they also determined that the conductivity coefficient increased (Figs. 7 and 8).

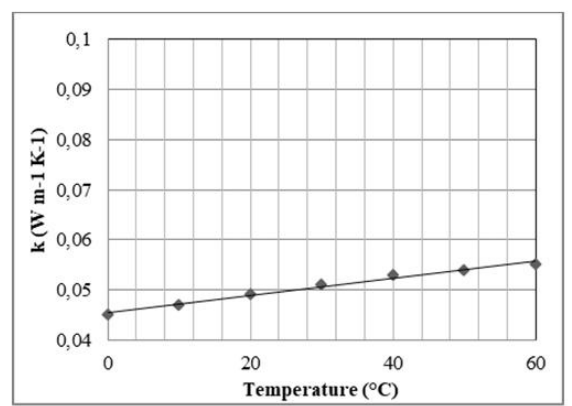

Fig. 7: Thermal conductivity coefficient according to temperature at $0 \%$ moisture content. (Troppova et al. (2015)).

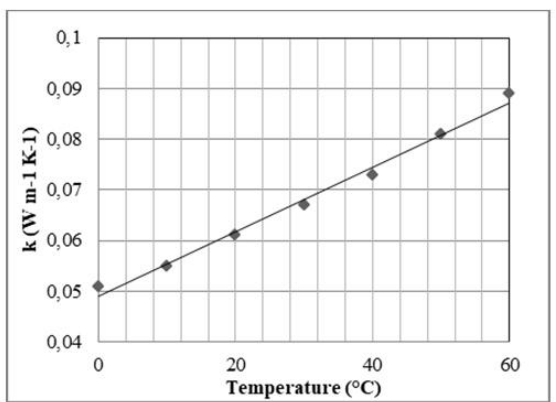

Fig. 8: Thermal conductivity coefficient according to temperature at $14.29 \%$ moisture content. (Troppova et al. (2015)).

In addition, Esen et al. (2012) stated in their study that the increase in temperature and humidity values would lead to an increase in the thermal conductivity coefficient in the wood material and they determined that the thermal conductivity coefficient of the fir wood material exposed to the sea effect increased compared to the original sample (Fig. 9). Kol (2009) in her study determined that the thermal conductivity coefficient of 5 different wood species changed with the effect of temperature and humidity and stated that the thermal conductivity of all wood species increased with the increase of temperature and humidity (Fig. 10). 


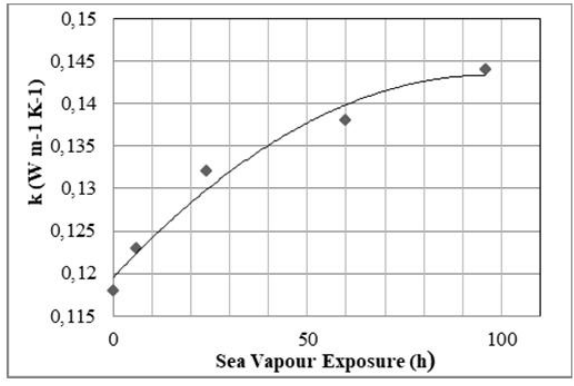

Fig. 9: Thermal conductivity coefficient according to sea vapour exposure. (Esen et al. (2012)).

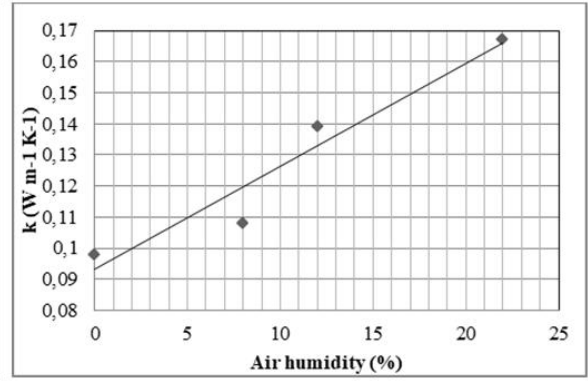

Fig. 10: Thermal conductivity coefficient according to sea vapour exposure. (Kol (2009)).

Trochonowicz et al. (2018) examined the change in air temperature and humidity and thermal conductivity coefficients of the wood based materials and he selected and showed similarly to the studies in the literature that thermal conductivity is dependent on humidity and temperature values (Fig. 11 and Fig. 12).

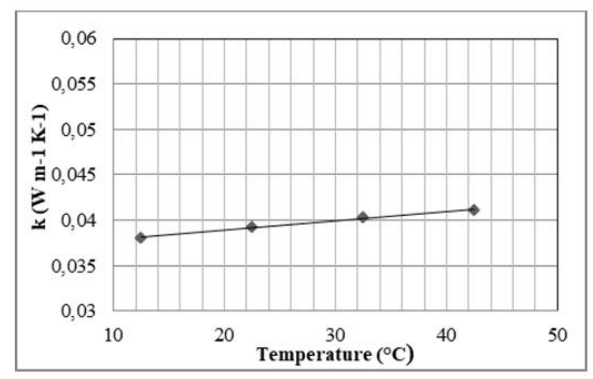

Fig. 11: Thermal conductivity coefficient according to temperature. (Trochonowicz et al. (2018)).

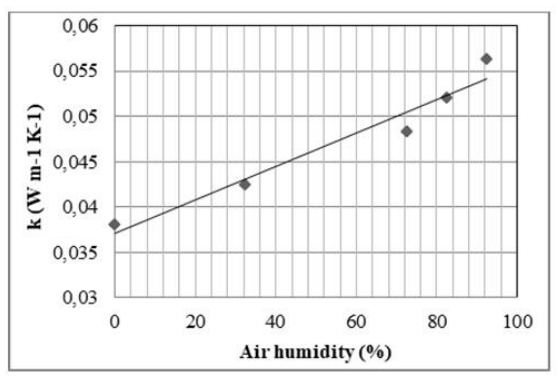

Fig. 12: Thermal conductivity coefficient according to air humidity. (Trochonowicz et al. (2018)).

Examples can be increased with this and similar studies. The common result is that the thermal conductivity coefficient of wood materials is directly related to humidity and temperature. In addition, being open to the sea effect, salinity, wind, etc. are also effective on the thermal conductivity values of wood materials.

\section{CONCLUSIONS}

Every historical building is a unique research subject with its inestimable cultural value; nevertheless the Florya Ataturk Marine Mansion can serve as a reference for the huge number of buildings alongside the Bosporus that suffers similar problems. As the mansion is opened to public as "Atatürk Museum" since 1993, the internal microclimate was also monitored and evaluated according to the recommended values for the materials preserved and human comfort requirements. The thermo-hygrometric conditions outside were measured for one year, whilst 
specific campaigns were performed to investigate indoor surface temperature and wall moisture content. According to obtained results, it was well understood that thermal conductivity coefficient of the building facade material, pinewood, varies in direct proportion to outside temperature and the moisture content of the material. As a result of the measurements taken from the mansion, a linear correlation was observed between the heat transfer coefficient of the wood and the temperature. This correlation $\left(y=0.0061 x+0.0876, R^{2}=0.8772\right)$ is compatible with the Fourier heat equation.

Similarly, a linear relationship $\left(y=0.05 x+0.0746, R^{2}=0.9952\right)$ between air humidity and heat transfer coefficient was observed according to measurements. Therewithal, while the maximum " $\mathrm{k}$ " value $\left(\mathrm{k}=0.26 \mathrm{~W} \mathrm{~m}^{-1} \cdot \mathrm{K}^{-1}\right)$ as obtained at summer months and front facade (as having most sunbathing time), the minimum one $\left(\mathrm{k}=0.18 \mathrm{~W} \mathrm{~m}^{-1} \cdot \mathrm{K}^{-1}\right)$ was obtained at winter months and left facade as exactly opposite. The results of this research could provide useful information for the future better preservation of the building and its content, thus reducing maintenance and restoration work and improving the internal conditions in terms of conservation requirements and human comfort issues. Also, the results which are obtained in this project can contribute to elaborate the more appropriate conservation strategy for the Mansion and also for other similar buildings threatened by the risks related to the marine environment.

\section{REFERENCES}

1. Abuamoud, M., Ates, S., Durmaz, E., 2018: Comparison of some anatomical, chemical and fibrous characteristics of Turkish Red pine (Pinus brutia Ten.) sampled from different region. Kastamonu University. Journal of Forestry Faculty 18(1): 75-82.

2. Abuku, M., Janssen, H., Roels, S., 2009: Impact of wind driven rain on historic brick wall buildings in moderately cold and humid climate: Numerical analyses of mould growth risk, indoor climate and energy consumption. Energy and Buildings 41(1): 101-110.

3. Alao, O., Alexander, M., Beushausen, H., 2014: Understanding the influence of marine microclimates on the durability performance of RC structures. In: Construction materials and structures (Eds. Ekolu SO, et al.). IOS Press, Pp 1537.

4. Becherini, F., Bernardi, A., Frassoldati, E., 2010: Microclimate inside a semi-confined environment: valuation of suitability for the conservation of heritage materials. Journal of Cultural Heritage 11(4): 471-476.

5. Becherini, F., Bernardi, A., Vivarelli, A., Pockelé, L., De Grandi, S., Gandini, A., García, O., Zubiaga, M., Espada Suárez, J.C., Sperandio, B., 2013: Environmental risk assessment and preventive conservation strategy for the porch of the glory. Santiago of Compostela Cathedral. Journal of Environmental Science and Engineering B2, Pp 299-303.

6. Bernardi, A., 2008: Microclimate inside cultural heritage buildings. Prato, Padova, 171 pp.

7. Camuffo, D., 2014: Microclimate for cultural heritage. Elsevier, Amsterdam, 560 pp.

8. Camuffo, D., Pagan, E., Bernardi, A., Becherini, F., 2004: The impact of heating, lighting and people in re-using historical buildings: a case study. Journal of Cultural Heritage 5(4): 409-416.

9. Chabas, A., Jeannette, D., Lefevre, R.A., 2000: Crystallization and dissolution of airborne sea-salts on weathered marble in a coastal environment at Delos (Cyclades Greece). Atmospheric Environment 34(2): 219-224. 
10. Davide, B., 2014: Salt deterioration and microclimate in historical Buildings. Intermediary report of the project. Institut für Denkmalpflege, Forschungsstelle Technologie und Konservierung, ETH Zürich, Pp 1-10.

11. Dell'Isola, M., D’Ambrosio Alfano, F.R., Giovinco, G., Ianniello, E., 2012: Experimental analysis of thermal conductivity for building materials depending on moisture content. International Journal of Thermophysics 33(8-9): 1674-1685.

12. Donovan, P.D., 1986: Protection of metals from corrosion in storage and transit. Wiley, New York, 228 pp.

13. Erkal, A., D’Ayala, D., Sequeira, L., 2012: Assessment of wind-driven rain impact, related surface erosion and surface strength reduction of historic building materials. Building and Environment 57: 336-348.

14. Esen, R., Ozcan, C., Likos, E., Ozkan, O.E., 2012: The effects of exposure to sea water steam on thermal conductivity of varnished fir wood. Kastamonu University. Journal of Forestry Faculty, special issue, Pp 217-220.

15. Fojtik, R., 2019: Moisture content analysis of wooden bridges. Wood Research 64(3): 529-536.

16. Grinzato, E., Bison, P.G., Smarinetti, S., 2002: Monitoring of ancient buildings by the thermal method. Journal of Cultural Heritage 3(1): 21-29.

17. Kilıc, A., Sariusta, S.E., Hafizoglu, H., 2010: Chemical structure of compression wood of Pinus sylvestris, P. nigra and P. brutia. Journal of Bartin Faculty of Forestry 12(18): 33-39.

18. Kol, H.S., 2009: Pine thermal, dielectric properties. BioResources 4(4): 1663-1669.

19. Meira, M.C., Andrade, I.J., Padaratz, M.C., Alonso, J.C., Borba, J.R., 2006: Measurements and modelling of marine salt transportation and deposition in a tropical region in Brazil. Atmospheric Environment 40: 5596-5607.

20. Michalski, S., 1990: Towards specific lighting guidelines. International Commission of Museums-Committee for Conservation. $9^{\text {th }}$ Triennial Meeting, Dresden, Pp 583-588.

21. Mills, J., White, R., 1987: The organic chemistry of museum objects. London, 165 pp.

22. Moradias, P.A., Silva, P.D., Castro-Gomes,J.P., Salazar, M.V., Pires, L., 2012: Experimental study on hygrothermal behaviour of retrofit solutions applied to old building walls. Construction and Building Materials 35: 864-873.

23. Morcillo, M., Chico, B., Mariaca, L., Otero, E., 2000: Salinity in marine atmospheric corrosion: its dependence on the wind regime existing in the site. Corrosion Science 42(1): 91-104.

24. Nava, S., Becherini, F., Bernardi, F., Bonazza, A., Chiari, M., Garcia, I., Lucarelli, F., Ludwig, N., Migliori, A., Sabbioni, C., Udisti, R., Valli, G., ve Vecchi, R., 2010: An integrated approach to assess air pollution threats to cultural heritage in a semi-confined environment: The case study of Michelozzo's Courtyard in Florence (Italy). Science of the Total Environment 408: 1403-1413.

25. Stefanis, A., Theoulakis, P., Pilinis, C., 2005: The decay effects of sea-salt aerosol on the surface of historic buildings. In Proceedings of the $9^{\text {th }}$ International Conference on Environmental Science and Technology. Rhodes Island, Greece, 1-3 September 2005, Pp 432-437.

26. Thomson, G., 1986: The museum environment. 2nd edition. London, 293 pp.

27. Trochonowicz, M., Galas, M., 2018: Influence of air humidity and temperature on thermal conductivity of wood-based materials. Budownictwo i Architektura 17(4): 77-86.

28. Troppova, E., Svehlık, M., Tippner, J., Wimmer, R., 2015: Influence of temperature and moisture content on the thermal conductivity of wood-based fibreboards. Materials and Structures 48(12): 4077-4083. 
29. Tutus, A., Kurt, R., Alma, M., Meric, H., 2010: Chemical analysis of Scotch pine wood and its thermal properties. In: Proceedings of the $3^{\text {rd }}$ National Black Sea Forestry Congress. Artvin, Turkey, 20-22 May 2010, Pp 1845-1851.

30. Zborowska, M., Babinski, L., Gajewska, J., Waliszewska, B., Pradzynski, W., 2007: Physical and chemical properties of contemporary pine wood (Pinus Sylvestris L.). In: Conditions of a wet archaeological site in Biskupin. Folia Forestalia Polonica, Series A 38(1): 13-26.

31. Zezza, F., Macrì, F., 1995: Marine aerosol and stone decay. The Science of Total Environment 167(1): 123-143.

\author{
Esra Celik, Ismail Cengiz Yilmaz* \\ Istanbul Arel University \\ Faculty of Engineering and Architecture \\ Department of Civil Engineering \\ ISTANBUL \\ TURKEY \\ *Corresponding author: cengizyilmaz@arel.edu.tr \\ Deniz Yilmaz \\ Istanbul Arel University \\ Faculty of Engineering and Architecture \\ Department of Mechanical Engineering \\ IsTANBUL \\ Turkey
}

